\title{
Modified coal fly ash as low cost adsorbent for removal reactive dyes from batik industry
}

\author{
Agus Taufiq, Pratikno Hidayat, Arif Hidayat ${ }^{*}$ \\ Chemical Engineering Department, Universitas Islam Indonesia, Indonesia
}

\begin{abstract}
The removal of reactive dyes on modified coal fly ash has been investigated during a series of batch adsorption experiments. Physical characteristics of modified coal fly ash was characterized by Brunauer Emmett Teller (BET) surface area analysis, X-ray powder diffraction (XRD), Fourier transform infrared spectrophotometer (FT-IR), and scanning electron microscope (SEM). The effects of operational parameters such as initial dye concentration $(50-200 \mathrm{mg} / \mathrm{L})$, solution $\mathrm{pH}(4-10)$ and adsorbent dosage $(50-200 \mathrm{mg} / \mathrm{L})$ were studied. The adsorption experiments indicated that modified coal fly ash was effective in removing of Remazol Blue. The percentage removal of dyes increased while the modified fly ash dosage increased. The percentage removal of dyes increased with decreased initial concentration of the dye and also increased with amount of adsorbent used. The optimum of removal of dyes was found to be $94 \%$ at initial dye concentration $50 \mathrm{~g} / \mathrm{mL}$, modified fly ash dosage $250 \mathrm{~g} / \mathrm{mL}$, and $\mathrm{pH}$ of 2.0 .
\end{abstract}

\section{Introduction}

A large number of dyes are produced annually and applied in various industries, including textiles, cosmetics, paper, leather, pharmaceuticals and food. Synthetic dyes and pigments are extensively used for dyeing and printing in industry. The textile industry accounts for two-thirds of the total dye market, consuming mostly reactive azo dyes due to the high demand for cotton fabrics with brilliant colors. In process of dyeing and printing colored products on textile industry, wastewater contaminated with dyes is generated. Discharge of hazardous wastewater without further treatment can seriously damage the environment. The colored discharged effluents inhibit penetration of sunlight and oxygen which are crucial requirements of aquatic life. Biodegradation of dyes is not an easy process due to their toxic and complex aromatic structure.

The dyes used in the textile industry are classified into three classes: (i) anionic dyes (direct, acid, and reactive), (ii) cationic, and (iii) nonionic. Basic and reactive dyes are widely used in the textile industry because of its favorable characteristics with bright colors, easy soluble in water, simple application techniques, and low energy consumption. Some dyes are toxic and carcinogenic and require separation and further treatment of textile wastes prior to discharge into environment.

Removals of dyes from water and wastewaters have been investigated intensively in last decades. The methods of dyes removal include biological, physical (membrane filtration, adsorption, coagulation, flocculation, precipitation, reverse osmosis, ion exchange, etc.) and chemical (oxidation, ozonation, etc.) processes. However, most of these methods exhibit major drawbacks, such as a high operational cost and low efficiency. Adsorption is a suitable physical process for the removal of low concentration of dyes and pigments. On adsorption method, the dyes and pigments would accumulate on the surface of solids at the interface between two phases (liquid-solid interface or gas-solid interface). The substance that accumulates at the interface is called adsorbate and the solid on which adsorption occurs is adsorbent. The system is easily regenerated and desorption may take place with modification of physical and chemical conditions. Porous structure of the adsorbent, chemical nature of the surface and $\mathrm{pH}$ of the aqueous solution act as major parameters in adsorption and desorption processes. Adsorption can be classified into two types: chemical sorption and physical sorption. Chemical adsorption or chemisorption is illustrated by the formation of strong chemical associations between molecules or ions of adsorbate to adsorbent surface. Chemisorption is generally due to the exchange of electrons and thus chemisorption is irreversible. Physical adsorption or physisorption is characterised by weak van der Waals intraparticle bonds between adsorbate and adsorbent and thus reversible in most cases.

Coal fly ash is a byproduct of coal combustion generated in power plant. Coal fly ash is generated at temperature of $1200-1700{ }^{\circ} \mathrm{C}$ from the various constituents of the coal. Each year nearly 42 million tons of coal is used in the Indonesia to generate electricity at the power plant. Currently, its applications are limited to as cement and brick and as a filling in road works. Research is therefore needed to develop new alternative environmental friendly applications. The high percentage of silica and alumina in fly ash makes it a good candidate for utilization as an inexpensive adsorbent for dyes removal.

\footnotetext{
* Corresponding author: arif.hidayat@uii.ac.id
} 
Numerous approaches have been found in the literature regarding the adsorption of chemical dyes on various adsorbents such as rice husk [1], peanut shell [2], coconut shell [2], coffee residues [4], eggshells [5], clay [6] etc. In the last few decades, fly ash, by-product from coal combustion in thermal power plants, has been used as an adsorbent in removal of dyes from water and wastewaters. Due to environmental considerations, coal fly ash are considered to be an adsorbent because they are cheap, available at large quantities and easily accusable sources. Saakshy et al. (2016) have studied the adsorption of direct black dye onto fly ash. It has been found that fly ash is a potential low cost adsorbent to treat effluent of handmade paper industry. Jarusiripot C. (2014) have investigated the removal of reactive dye in aqueous solution on coal bottom ash. The coal bottom ash was pretreated with $1 \mathrm{~N} \mathrm{HCl}_{1} 1 \mathrm{~N} \mathrm{HNO}_{3}$, and $30 \% \mathrm{H}_{2} \mathrm{O}_{2}$ before the adsorption tests. Visa and Chelaru (2015) investigated the adsorption behavior of modified fly ash in wastewater treatment for removal of dyes by adsorption. Ferrero (2015) studied the removal of acid and basic dyes from aqueous solution using coal fly ash. In another work, the removal of disperse blue and disperse orange dyes by coal fly ash from aqueous solutions was studied by Kisku et al. (2015).

Although several investigations have been reported on removal of textile dyes using fly ash, more information is still needed for better understanding of the adsorption behavior of dyes on fly ash. The purpose of this study was to investigate the adsorption of reactive dyes on modified coal fly ash, which is a low cost adsorbent, very abundant and inexpensive material. The effects of initial dye concentration, solution $\mathrm{pH}$, contact time, and adsorbent dosage on the adsorption of reactive dyes on modified coal fly ash were studied.

\section{Methodology}

\subsection{Material}

The main raw material, coal fly ash samples is collected from electrostatic precipitators of Suralaya power plants, West Java. The samples contains both amorphous (mainly $\mathrm{SiO}_{2}, \mathrm{Al}_{2} \mathrm{O}_{3}$ ) and crystalline components (mainly quartz and mullite). Prior to an experiment, the the raw coal fly ash samples is dried at $300{ }^{\circ} \mathrm{C}$ for $48 \mathrm{~h}$ in order to remove any traces of moisture or other contaminants. Then, the size of coal fly ash is reduced to a powder by crushing it in the ball mill and screening to get uniform size distribution. The coal fly ash is treated with concentrated hydrochloric acid (acid/ash= $5 \mathrm{ml} / \mathrm{g}$ ) at a temperature of $70{ }^{\circ} \mathrm{C}$ for $1 \mathrm{~h}$. The acid treatment removed iron to a certain extent, thereby increasing the activity, thermal stability and acidity of the zeolite, all aiming for better catalytic applications. And then, the sample is then neutralized by adding $\mathrm{H}_{2} \mathrm{O}$ until the $\mathrm{pH}$ of the sample is 7 . Then, the samples were characterized using Brunauer Emmett Teller (BET) surface area analysis, X-ray powder diffraction (XRD), Fourier transform infrared spectrophotometer (FT-IR), and scanning electron microscope (SEM). The dyes used in the adsorption experiments was Remazol Blue R which obtained from a batik industry.

\subsection{Adsorption study}

Batch experiments were carried out to measure the adsorption characteristics of Remazol Blue on modified coal fly ash. Prior to their use, the adsorbents were ovendried at $378 \mathrm{~K}$ for $4 \mathrm{~h}$ to eliminate traces of moisture. A certain amount of the modified coal fly ash sample was added to $50 \mathrm{ml}$ of dye solution of varying concentration $(50,100,150,200 \mathrm{mg} / \mathrm{L})$ in a $250 \mathrm{ml}$ conical flask. The mixture was agitated in a temperature controlled shaker at a constant speed of $250 \mathrm{rpm}$ for $24 \mathrm{~h}$ at a constant temperature of $298 \mathrm{~K}$. After stirring, the mixtures were separated by filtering. The residual concentration of dye solution was determined using a calibration curve prepared at the corresponding maximum wavelength using a UV-visible spectrometer. The effect of $\mathrm{pH}$ was studied for Remazol Blue dye of $50 \mathrm{mg} / \mathrm{L}$ concentration at $\mathrm{pH} 4,6,8$ and 10 . The $\mathrm{pH}$ was maintained with the addition of $1 \mathrm{~N} \mathrm{NaOH} \mathrm{mg/L} \mathrm{and} 1 \mathrm{~N} \mathrm{HCl}$. The effect of adsorbent dosage was also studied at 4, 5, 10 and $20 \mathrm{~g} / \mathrm{L}$ at optimized $\mathrm{pH}$ and initial dye concentration.

The percentage removal and amount adsorbed were calculated by the following equation:

$$
\% \text { removal of dye }=\frac{C_{0}-C_{e}}{C_{0}} \times 100
$$

Where: $C_{0}$ is the initial concentration of dye and $C e$ is the concentration of dye at equilibrium

\section{Results and Discussion}

\subsection{Material Characterization}

The textural characteristics of fly ash were studied by using the $\mathrm{N}_{2}$ adsorption method. The well-known Brunnauer-Emmett-Teller (BET) equation was used for the calculation of specific surface area, SBET, pore volume, $\mathrm{V}$, and the average pore diameter, $\mathrm{R}$. The results for raw (RFA) and modified fly ash (MFA) are given in Table 1. It reveals that the acid treatment enhances the surface area and pore volume of the RFA, while decreases its average pore diameter. This may be explained by the increasing micropore content of the MFA after the impurities and organics were removed by acid and water.

Table 1. Surface area and pore size of raw and treated fly ash

\begin{tabular}{|c|c|c|}
\hline Material & Raw FA & Modified FA \\
\hline $\mathrm{S}_{\text {BET }}\left(\mathrm{m}^{2} / \mathrm{g}\right)$ & 4,975 & 45,716 \\
\hline $\mathrm{V}_{\text {total }}\left(\mathrm{cm}^{3} / \mathrm{g}\right)$ & 0,0137 & 0,1572 \\
\hline Pore diameter $(\mathrm{nm})$ & 13,66 & 11,99 \\
\hline
\end{tabular}

The SEM photographs of RFA and MFA are shown in Figure 2. It can be seen that the surface morphology of RFA is slightly changed by the acid treatment. The SEM 
image clearly shows that the particles are mainly composed of irregular and porous particles.

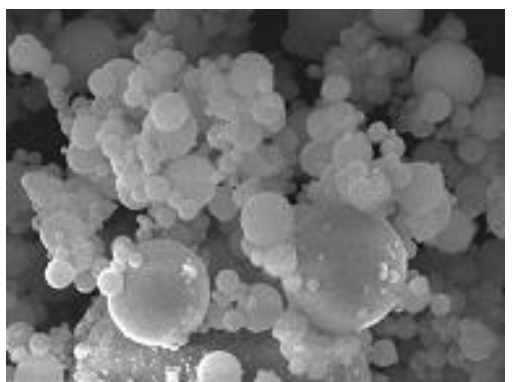

(a)

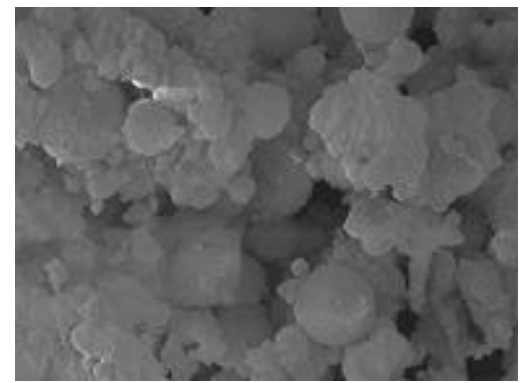

(b)

Fig. 2. SEM paragraphs of (a) RFA and (b) MFA.

The XRD of RFA and MFA are shown in Figure 2. It is seen that there are not significant difference for all XRD profiles. But acid-treated samples present higher intensity of diffraction peaks. The major phases for all samples are quartz and mullite. Some minor phases, hematite and magnetite, are also existed. Those results suggest that acidtreatment will not induce bulk phase changes.

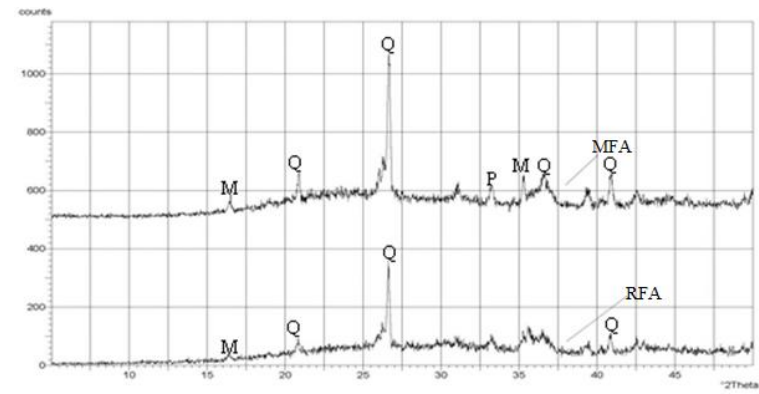

Fig. 3. The XRD patterns of (a) RFA and (b) MFA.

An FTIR analysis was performed in the range of 450$4000 \mathrm{~cm}^{-1}$ in order to explore the surface characteristics of the samples. Figure 3 shows the FTIR spectrum of RFA and MFA. The band at $3200-3500 \mathrm{~cm}^{-1}$ is due to stretch vibration $(\mathrm{O}-\mathrm{H})$. Moreover, the absorption bands at $1620-1650 \mathrm{~cm}^{-1}$ were caused by deformational vibrations of adsorbed water molecules. Spectrum of the treated fly ash possesses three absorption bands, at 1084; 793, and $466 \mathrm{~cm}^{-1}$. The 1084 and $466 \mathrm{~cm}^{-1}$ bands are due to the asymmetric stretching and the bending vibration modes of M-O bonds, respectively (where $\mathrm{M}=\mathrm{Si}$ or $\mathrm{Al}$ ). The 793 $\mathrm{cm}^{-1}$ band is assigned to the symmetric stretching vibration mode of O-M-O groups.

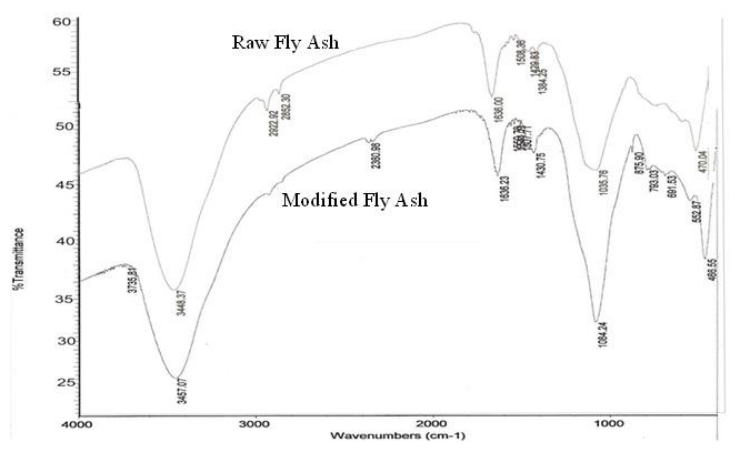

Fig. 4. FTIR spectra of raw and modified fly ash.

It has been seen that yield of the process increases with increase in molar ratio. With further increase in molar ratio the conversion efficiency more or less remains the same. However it can be concluded that the molar ratio increased from 10:1 to 12:1 there is no significant change observed with a higher molar ratio in the reduction of FFA. The maximum conversion efficiency is achieved very close to the molar ratio of 12:1.

\subsection{Effect of initial dye concentration}

The experimental results of removal of dyes on modified fly ash at various concentrations $(50,100,150$, and 200 $\mathrm{mg} / \mathrm{L}$ ) are shown in Figure 4. During removal of dyes, initially the dye molecules reach the boundary layer; then they have to diffuse into the adsorbent surface; and finally, diffuse into the porous structure of the adsorbent. It was observed that the percentage removal of dyes reached up to $94 \%$ at lower concentration. When the initial dye concentration was increased, the percentage removal of dyes increased. The percentage removal of dyes decreased with increasing the initial dye concentration because of nearly complete coverage of the binding sites at high dye concentration. The effect of initial dye concentration on removal of dyes could be attributed to the increase in the driving force of the concentration gradient with an increase in the initial dye concentration.

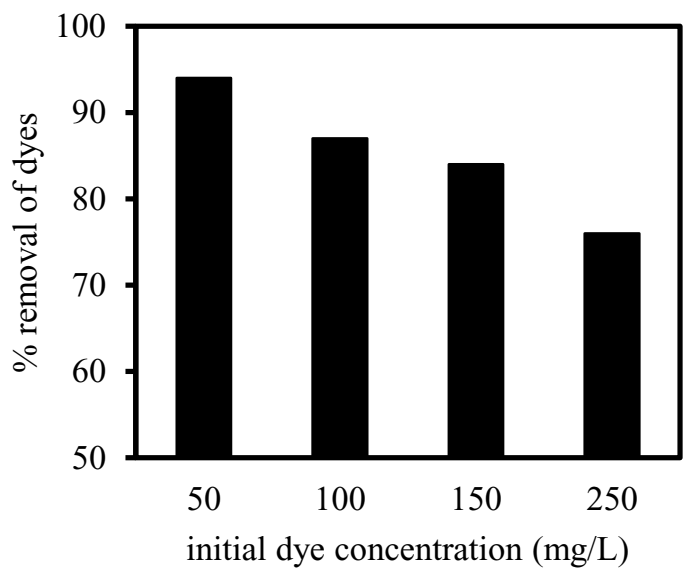

Fig. 5. Effect of initial dye concentration on removal of dyes.

\subsection{Effect of modified fly ash dosage}

The removal of dyes on modified fly ash dosage was studied by varying the modified fly ash dosage (50-200 
$\mathrm{mg} / \mathrm{L}$ ) at $\mathrm{pH}$ 6.0. The removal of dyes at various dosages of modified fly ash is shown in Figure 5. The percentage removal of dyes increased while the modified fly ash dosage increased. The percentage removal of dyes increased from $78,81,89$, to 94 for the modified fly ash dosage 50,100,150, and $200 \mathrm{mg} / \mathrm{L}$, respectively. This can be attributed to increased adsorbent surface area and availability of more adsorption sites.

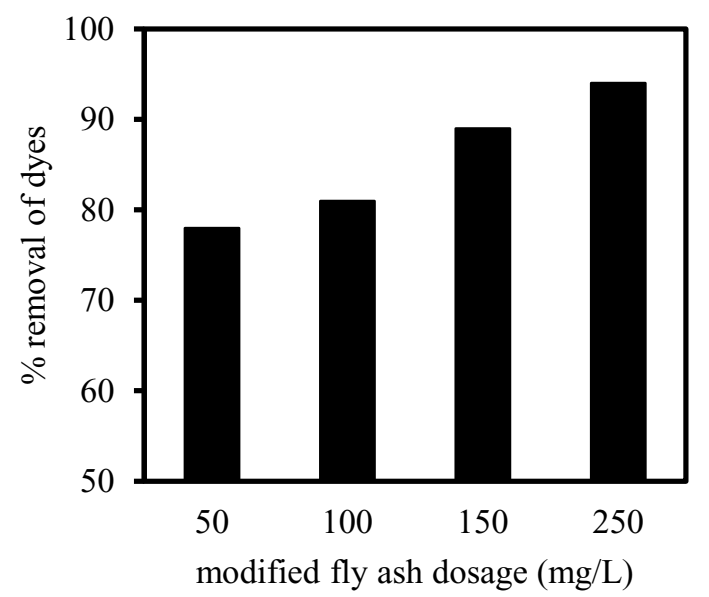

Fig. 6. Effect of modified fly ash dosage $(\mathrm{pH} 6$, initial dye concentration $50 \mathrm{mg} / \mathrm{l}$, temperature $30^{\circ} \mathrm{C}$, stirring speed 250 rpm).

\subsection{Effect of solution pH}

One of the most important factors affecting the capacity of adsorbent in removal of dyes is solution $\mathrm{pH}$. The percentage removal of dyes is dependent on the solution $\mathrm{pH}$, since variation in $\mathrm{pH}$ leads to the variation in the degree of ionisation of the adsorptive molecule and the surface properties of adsorbent (Nandi, 2009). The study was carried out with modified fly ash fly ash of dosage 5 $\mathrm{g} / \mathrm{L}$ on reactive dye of $50 \mathrm{mg} / \mathrm{L}$ concentration maintained at $\mathrm{pH}$ from 4 to 10 . The removal of dyes by fly ash at various $\mathrm{pH}$ is shown in Figure 6. The removal of dyes increased when the final $\mathrm{pH}$ was increased from 2.5 to 8.5. After these $\mathrm{pH}$ ranges, the removal of dyes slightly decreased. In general, at low solution $\mathrm{pH}$, the percentage of removal of dyes will decrease for cationic dye adsorption, while for anionic dyes the percentage of dyes removal will increase. In contrast, high solution $\mathrm{pH}$ is preferable for cationic dye adsorption but shows a lower efficiency for anionic dye adsorption. At high solution $\mathrm{pH}$, the positive charge at the solution interface will decrease while the adsorbent surface appears negatively charged. As a result, the cationic dye adsorption will show an increase and the anionic dye adsorption will decrease. At low $\mathrm{pH}$ solution, the positive charge on the solution interface will increase and the adsorbent surface will appear positively charged, which results in decrease in cationic dye adsorption and an increase in anionic dye adsorption.

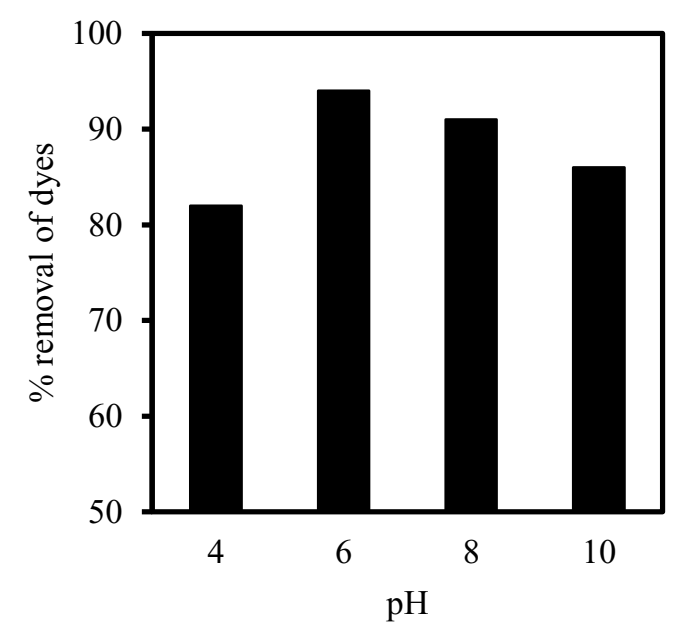

Fig. 7. Effect of $\mathrm{pH}$ (initial dye concentration $50 \mathrm{mg} / \mathrm{L}$, fly ash dosage $50 \mathrm{mg} / \mathrm{L}$, temperature $30^{\circ} \mathrm{C}$, stirring speed $250 \mathrm{rpm}$ ).

\section{Conclusions}

The adsorption experiments indicated that modified coal fly ash was effective in removing of Remazol Blue. The percentage removal of dyes increased while the modified fly ash dosage increased. The percentage removal of dyes increased with decreased initial concentration of the dye and also increased with amount of adsorbent used. The optimum of removal of dyes was found to be $94 \%$ at initial dye concentration $50 \mathrm{~g} / \mathrm{mL}$, modified fly ash dosage 250 $\mathrm{g} / \mathrm{mL}$, and $\mathrm{pH}$ of 2.0 .

The adsorption experiments indicated that modified coal fly ash was effective in removing of Remazol Blue. The percentage removal of dyes increased while the modified fly ash dosage increased. The percentage removal of dyes increased with decreased initial

\section{References}

1. L. Leng, X. Yuan, G. Zeng, J. Shao, X. Chen, Z. Wu, H. Wang, X. Peng, Fuel, 155, 77-85 (2015)

2. J. Georgin, G.L. Dotto, M.A. Mazutti, E.L. Foletto, Journal of Environmental Chemical Engineering, 4 (1), 266-275 (2016)

3. A.M. Aljeboree, A.N. Alshirifi, A.F. Alkaim, Arabian Journal of Chemistry, 10, Supplement 2, s3381-s3393 (2017)

4. G.Z. Kyzas, N.K. Lazaridis, A.Ch. Mitropoulos,. Chemical Engineering Journal, 189-190, 148-159 (2012)

5. M.A. Abdel-Khalek, M.K. Abdel Rahman, A.A. Francis, Journal of Environmental Chemical Engineering, 5 (1), 319-327 (2017)

6. S.C.R. Santos, R.A.R. Boaventura, Journal of Environmental Chemical Engineering, 4 (2), 14731483 (2016)

7. Saakshy, K. Singh, A.B. Gupta, A.K. Sharma Journal of Cleaner Production, 112 (1), 1227-1240 (2016) 
8. C. Jarusiripot, Procedia Chemistry, 9, 121-130 (2014)

9. Visa M., Chelaru A. M. Applied Surface Science, 303, 14-22 (2014)

10. Ferrero F., Clean Technologies and Environmental Policy, 17 (7), 1907-1915 (2015)

11. G.C. Kisku, Markandeya, S.P. Shukla, D.Sen Singh, R.C. Murthy, 74 (2), 1125-1135 (2015)

12. B. Nandi, A. Goswami, M. Purkait, Appl Clay Sci, 42 (3-4), 583-590 (2009) 